\title{
Correction to: Cr(VI) Removal from Aqueous Solution Using a Magnetite Snail Shell
}

\author{
Le Phuong Hoang - Thi Minh Phuong Nguyen • \\ Huu Tap Van • Thi Kim Dung Hoang • Xuan Hoa Vu • \\ Tien Vinh Nguyen • N. X. Ca (1)
}

Published online: 31 March 2021

(C) Springer Nature Switzerland AG 2021

\section{Correction to: Water Air Soil Pollut (2020) 231: 28 https://doi.org/10.1007/s11270-020-4406-4}

There was an error in SEM image and EDS data in Fig. 2 (a and d), respectively, (SEM and EDS of (a, d) snail shell (SS), (b, e) magnetic snail shell (MSS25), and (c, f) magnetic snail shell after Cr(VI) adsorption (MSS2525)). It is replaced with the following Fig. 1S

The online version of the original article can be found at https://doi.org/10.1007/s11270-020-4406-4

\section{P. Hoang $\cdot$ T. K. D. Hoang}

Faculty of Civil and Environmental Engineering, Thai Nguyen University of Technology (TNUT), TichLuong Ward, Thai Nguyen, Vietnam

\section{T. M. P. Nguyen}

Faculty of Environment and Chemical Engineering, Duy Tan University (DTU), 254 Nguyen Van Linh road, Da Nang, Vietnam

H. T. Van

Faculty of Natural Resources and Environment, TNU - University of Sciences (TNUS), Tan Thinh ward, Thai Nguyen, Vietnam

X. H. Vu

Institute of Research and Development, Duy Tan University, Da Nang 550000, Vietnam

\section{T. V. Nguyen}

Faculty of Engineering and IT, University of Technology Sydney (UTS), Box 123, Broadway, Sydney, PO, Australia

N. X. Ca $(\bowtie)$

Laboratory of Advanced Materials Chemistry, Advanced Institute of Materials Science, Ton Duc Thang University, Ho Chi Minh City, Vietnam

e-mail: nguyenxuanca@tdtu.edu.vn

\section{N. X. Ca}

Faculty of Applied Sciences, Ton Duc Thang University, Ho Chi Minh City, Vietnam 
Fig. 1S. SEM and EDS of (a, d) snail shell (SS), (b, e) magnetic snail shell (MSS25), and (c, f) magnetic snail shell after $\mathrm{Cr}(\mathrm{VI})$ adsorption (MSS25-25) (replaced Fig. 2)

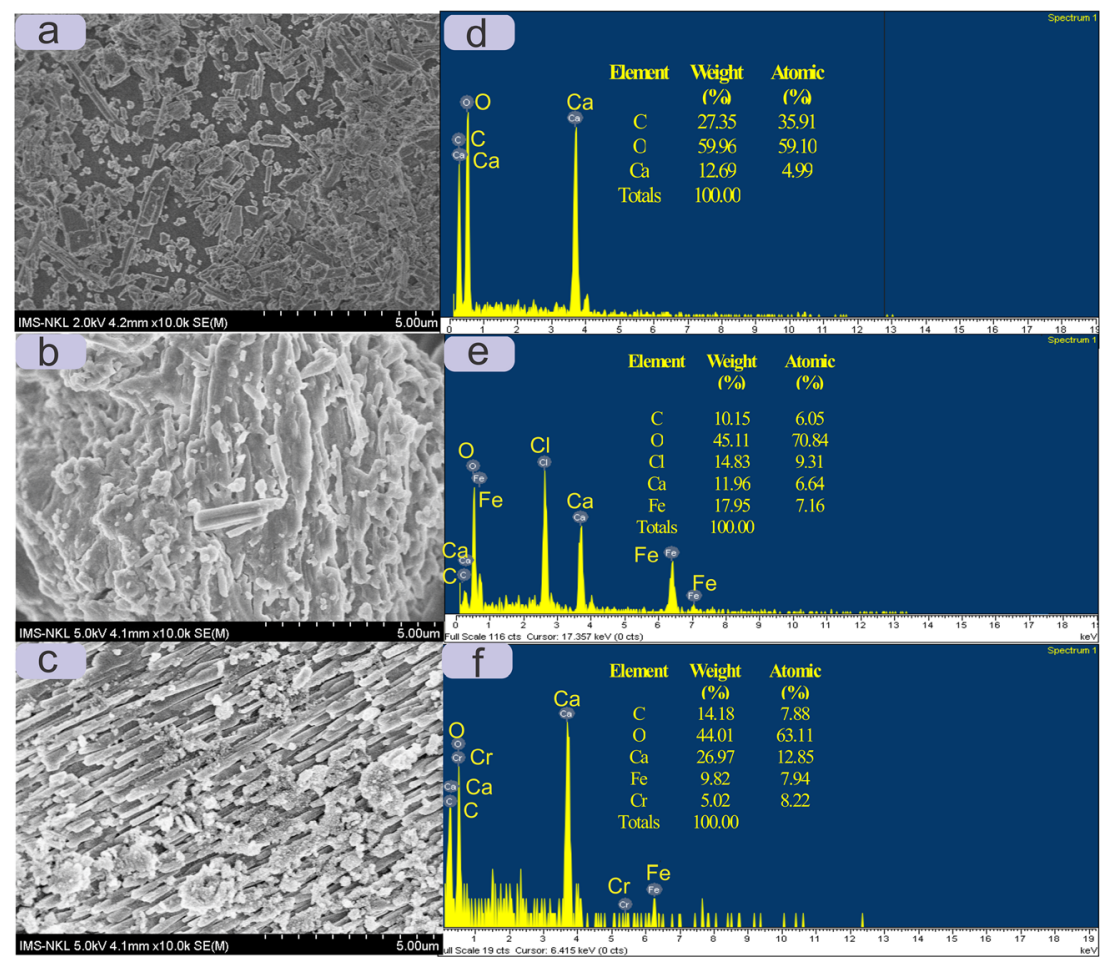

Publisher's Note Springer Nature remains neutral with regard to jurisdictional claims in published maps and institutional affiliations. 